\title{
A EFETIVIDADE DOS DIREITOS HUMANOS DE TERCEIRA GERAÇÃO: A ANÁLISE DE UM CASO VENEZUELANO*
}

\author{
Julia Lafayette Pereira** \\ Rafael Rott de Campos Velho*** \\ Jânia Maria Lopes Saldanha****
}

\begin{abstract}
RESUMO: O presente trabalho é um resultado parcial de um projeto maior que visa a estudar a efetividade dos direitos à saúde e ao meio ambiente na jurisprudência das Supremas Cortes dos países que compõem o Mercosul, bem como de seu Sistema Autônomo de Solução de Controvérsias. Esse artigo destina-se ao estudo de uma decisão da suprema corte venezuelana referente à permissão de uma empresa para importar gases CFCs. Primeiramente, o trabalho busca trazer as origens dos Direitos Humanos de terceira geração. Após isso, explana-se o caso do CFC e os danos à ozonosfera, passando pela regulamentação internacional. Após isso, passando por questões atinentes aos marcos regulatórios desses direitos na Venezuela. Por fim, faz-se a análise do caso.
\end{abstract}

PALAVRAS-CHAVE: Direitos Humanos. Meio Ambiente. Jurisdição. Análise caso.

ABSTRACT: This work is a partial result of a larger project which has the objective of studying the effectiveness of the Human Rights to health and to a healthy environment in the jurisprudence of the Supreme Courts of the countries that are members of Mercosur and also the cases submitted to its Autonomous System for Solving Controversies. This paper is about a decision from the Venezuela's Supreme Court about a permission of an enterprise to import CFC gas. Firstly, the work brought the origins of the Third Generation Human Rights. Than, it's explained the case of CFC and its damages to the ozone layer and, also, the international regulation for the CFC use. After that, it's made an analysis of the legislation about Third Generation Human Rights in Venezuela. Finally, the case is studied.

KEY-WORDS: Human Rights. Environment. Jurisdiction. Case analysis.

*Resultado parcial da pesquisa intitulada "O Sistema Autônomo de Solução de Controvérsias do Mercosul e as Cortes Supremas de Justiça dos seus Países-membros: Direitos Humanos e perspectivas para a consolidação da cidadania" desenvolvida com apoio do CNPq, sob coordenação da prof". Jânia Maria Lopes Saldanha.

**Acadêmica do Curso de Direito da Universidade Federal de Santa Maria. E-mail: julialafayette@ hotmail.com

***Acadêmica do Curso de Direito da Universidade Federal de Santa Maria. Bolsista de iniciação científica FIPE/UFSM. E-mail: rafael.campos.velho@gmail.com

**** Orientadora. Doutora em Direito pela Universidade do Vale do Rio Sinos (UNISINOS), mestre em Integração Latina Americana (MILA) pela Universidade Federal de Santa Maria (UFSM). Professor da UFSM, onde coordena o MILA e da pós-graduação stricto sensu da UNISINOS.

\section{INTRODUÇÃ̃O}

O Projeto intitulado "O sistema autônomo de solução de controvérsias do Mercosul e as Cortes Supremas de Justiça dos seus países membros: Direitos Humanos e perspectivas para a consolidação da cidadania" tem por escopo investigar a jurisprudência do Tribunal Permanente de Revisão do Mercosul, criado pelo protocolo de Olivos, e das cortes supremas de justiça dos países que compõem o bloco. Nesse sentido, o objetivo principal é analisar se o comportamento dessas jurisdições está de acordo com a globalização hegemônica ou contra-globalização ${ }^{1}$.

Para tanto, o objetivo inicial era investigar as decisões atinentes aos Direitos Humanos nas jurisdições supracitadas. Com o decorrer da pesquisa, o grupo decidiu-se

\footnotetext{
${ }^{1}$ Conceitos esses criados por Boaventura de Souza Santos (2001, p. 70-73). No texto, o sociólogo defende que para se combater a globalização puramente econômica, chamada de hegemônica, a qual visa apenas a expandir os mercados de capital, disseminado pelo mundo as idéias de uma economia liberal, não se deve retornar a um localismo, mas sim promover uma contra-globalização, ou seja, a necessidade de se implementar "trocas iguais" entre norte e sul, dentro de uma perspectiva da solidariedade. Para isso, devem existir "redes de solidariedade", personificada em tratados para proteção dos Direitos Humanos, organizações não governamentais (ONGs), movimentos artísticos, culturais e científicos, redes volt adas à proteção do meio-ambiente ou a buscar meios alternativos de desenvolvimento, entre muitos outros exemplos que poderiam ser aqui citados.
} 
por um corte epistemológico, voltando-se exclusivamente para questões referentes ao direito à saúde e ao meio-ambiente. Esses temas foram escolhidos devido ao fato de serem, aos olhos do grupo, os direitos que mais evidenciariam as posições adotadas pelas cortes. Isso se deve ao fato de serem direitos que não estão ainda tão consolidados como os direitos ditos de primeira geração ou individuais.

Nesse sentido, esse artigo tem como escopo fazer uma análise casuística de uma decisão adotada pela Suprema Corte venezuelana atinente, principalmente ao direito ao meio-ambiente. Vale ressaltar que o direito à saúde também se fez presente no caso em questão, o que será abordado no devido tempo.

Para se proceder a tal análise, esse trabalho se dividiu metodologicamente em duas grandes partes. A primeira tem escopo buscar um embasamento teórico, trabalhando com conceitos como os Direitos Humanos de terceira geração. A segunda parte subdivide-se em várias subseções. A Primeira tem como objeto trazer uma base de conhecimento sobre os CFCs e os danos causados por eles à camada de ozônio, bem como da busca por tentativas de regulamentação do uso dessas substâncias no atinente à Convenção de Viena sobre CFCs e ao Protocolo de Montreal. Após isso, procede-se à análise do caso venezuelano, passando por questões como os marcos regulatórios acerca do direito ao meio ambiente na carta constitucional do país em tela e a análise do caso propriamente dito. Por fim, faz-se presente uma tabela, definida pelo grupo de pesquisa para objetivar os dados colhidos, com o objetivo de demonstrar uma síntese do caso.

\section{DIREITOS HUMANOS DE TERCEIRA GERAÇÃO: O DIREITO A UM MEIO AMBIENTE SAUDÁVEL}

Na clássica divisão legada por Norberto Bobbio (1992), os Direitos Humanos se dividiriam em gerações. Assim afirma o autor:

do ponto de vista teórico, sempre defendi - e continuo a defender, fortalecido por novos argumentos - que os direitos do homem, por mais fundamentais que sejam, são direitos históricos, ou seja, nascidos em certas circunstâncias, caracterizadas por lutas em defesa de novas liberdades contra velhos poderes, e nascidos de modo gradual, não todos de uma vez e nem de uma vez por todas (BOBBIO, 1992, p. 5).

Dessa forma, nos direitos de primeira geração, estariam compreendidos aqueles clássicos, advindos, mormente, dos ideais burgueses da Revolução Francesa. O ícone dos direitos dessa geração é o direito à liberdade (compreendendo a liberdade de locomoção, de pensamento e de imprensa). Outros direitos civis como o direito à livre 
iniciativa, à propriedade privada, à privacidade, entre muitos outros, estão compreendidos nessa mesma seara.

Os direitos de segunda geração nascem com o surgimento da doutrina marxista e a busca por melhorias no quadro social. É sempre importante ressaltar que a doutrina comunista/socialista é uma conseqüência direta da Revolução Industrial e do quadro que se formou a partir desse fato. Trabalhadores explorados, sem direito algum, miserabilidade da população, entre outros fatores, foram decisivos para o surgimento de teorias que visavam a combater o status quo estabelecido. Dessa forma, os direitos sociais, ditos de segunda geração, podem ser vistos como os direitos trabalhistas, previdenciários, à saúde pública, ao lazer, etc.

Os Direitos Humanos de terceira geração, foco principal do presente trabalho, são os direitos transindividuais ou difusos. Eles se caracterizam por não poderem ser divididos pelos atores sociais, pertencem a todos ao mesmo tempo, não podendo ser concedidos a um ou a outro indivíduo de forma separada. Assim Bobbio (1992, p. 6) se refere a eles: "o mais importante deles é o reivindicado pelos movimentos ecológicos, o direito a viver em meio ambiente não poluído". Dessa forma, pode-se afirmar que tais direitos constituem uma verdadeira condição para que a vida possa continuar nesse planeta. Não se trata mais de direitos de alguns menos favorecidos frente aos detentores do poder, como observado nas primeiras gerações, e, sim, de direitos inerentes a todos, sem os quais a vida não poderá prosseguir no mundo.

É importante ressaltar que um dos problemas basilares no que se refere aos Direitos Humanos (ou fundamentais, sem querer adentrar na discussão que pretende diferenciá-los) é a sua eficácia. Assim, o professor Ingo Sarlet coloca que acima de tal divisão proposta, o mais importante seria a efetividade dos direitos fundamentais:

A despeito destes e de todos os demais aspectos que aqui poderiam ser versados e por mais que se possa aderir a boa parte das críticas colacionadas no que diz especialmente com a supervalorização histórica (dimensional) dos direitos fundamentais, cremos que o mais importante segue sendo a adoção de uma postura ativa e responsável de todos, governantes e governados, no que concerne à afirmação e à efetivação dos direitos fundamentais de todas as dimensões, numa ambiência necessariamente heterogênea e multicultural, pois apenas assim estar-se-á dando passos indispensáveis à afirmação de um direito constitucional genuinamente "altruísta" e "fraterno". (SARLET, 2004, p. 68)

Hodiernamente, a doutrina moderna (o próprio Bobbio chega a trazer os inícios em sua obra clássica) traz consigo o ideal do surgimento de novos direitos, classificando-os em direitos de quarta e quinta gerações. Os de quarta compreenderiam 
o bio-direito, a manipulação genética, entre outros e a quinta geração seria o direito virtual. Como não é foco do trabalho, a questão não será tratada com maior profundidade.

\section{A ANÁLISE DE UM CASO CONCRETO VENEZUELANO}

Nesse momento, passamos a analisar um caso concreto venezuelano. Consiste em uma decisão da suprema corte do país em tela, na qual o Direito ao meio ambiente foi invocado ao se proibir uma empresa de importar os hidrocarbonetos clorofluorcarbonos (CFCs). Nessa seção procuraremos passar por três pontos-chave: primeiramente, explicar conceitos acerca do CFC e seus males à camada de ozônio, passando pela regulamentação internacional acerca do tema; num segundo momento a análise dos dispositivo da Constituição Venezuelana que versem sobre meio-ambiente e sua tutela; e, por fim, um estudo da decisão.

\subsection{O caso do CFC e sua Regulamentação}

Os gazes CFCs surgiram em 1926, devido à intensa pesquisa na época para criar um gás próprio para o uso em aparelhos refrigeradores. Essa iniciativa deveu-se à necessidade de descobrir um gás não tóxico aos consumidores, visto que o uso de outros gazes nestes aparelhos, como a amônia, o cloreto de metil, entre outros, foram responsáveis por inúmeros acidentes fatais ocasionados por vazamentos, devido a extrema toxicidade destes.

De acordo com a Enciclopédia Britannica (1993, p.1), os CFCs reuniam características, aparentemente, ideais para as indústrias refrigeradoras por serem: inodoros, estáveis (devido à presença do elemento flúor), não inflamáveis, não corrosivos, não atraentes aos insetos e não venenosos. Devido a essas propriedades, eles foram largamente empregados pelas indústrias, não só pelas indústrias de aparelhos refrigeradores, como também pelas fabricadoras de aerosóis ${ }^{2}$, pois, mais tarde, descobriu-se que eles também eram próprios para a confecção destes.

Segundo dispõe o site Wikipédia:

Em 1930 a General Motors e a DuPont formaram a Kinetic Chemical Company para produzir o Freon. Em 1935 a Frigidaire e seus concorrentes já tinham comercializado em torno de 8 milhões de refrigeradores novos nos Estados Unidos. Em 1932, a Carrier Engineering Corporation usou o Freon na primeira unidade de ar condicionado. Fabricado pela empresa DuPont durante anos os

\footnotetext{
${ }^{2}$ Aerosol ou Aerossol é um conjunto de partículas suspensas num gás, com alta mobilidade intercontinental.
} 
CFCs foram usados e liberados livremente na atmosfera sem conhecimento dos danos que estavam causando para a humanidade e para o Planeta Terra, pois eram gases considerados seguros e estáveis.

No entanto, por meio dos anos 70, sugeriu-se que eles eram responsáveis por destruírem moléculas de ozônio $\left(\mathrm{O}_{3}\right)$, presentes na estratosfera, por meio de reações químicas, que acabava por causar danos na camada de ozônio. Tal sugestão, nos anos 80 , tornou-se comprovada.

Essa nova descoberta era de extrema gravidade, pois a rarefação da camada de ozônio é algo extremamente prejudicial à vida animal na Terra, haja vista que ela tem por função filtrar os raios ultravioletas (UV) para que não incidam na superfície terrestre. Segundo Usberco e Salvador (2000, p.215), a intensa radiação de raios UV é responsável pelo câncer de pele, por problemas visuais e até pela destruição de espécies vegetais. Sem a camada de ozônio, nem mesmo há a possibilidade das formas conhecidas de vida no planeta.

Nesse contexto, era necessária uma medida de urgência em âmbito internacional com o objetivo de regulamentar o uso desses gazes e, assim, evitar que o dano tomasse proporções ainda maiores ${ }^{3}$. Para tanto, foram criados, em 22 de março de 1985, a Convenção de Viena e, mais tarde, o Protocolo do Montreal, em 16 de setembro de 1987.

\subsubsection{A Regulamentação do CFC: A Convenção de Viena e o Protocolo de Montreal}

A Convenção de Viena tem como objetivo estimular a cooperação dos países signatários para a preservação da camada de ozônio. Tal ação é implementada por meio de pesquisas, tanto de "substâncias alternativas" 4 , como através da observação de alterações na ozonosfera.

Dessa forma, destina-se a estimular a substituição de gazes nocivos, como o CFC, por essas "substâncias alternativas" já citadas anteriormente. Prevê também o intercâmbio de informações referentes a novas descobertas, a inovações tecnológicas, a novas doenças em decorrência da destruição da camada de ozônio, entre outros. Acorda sobre mecanismos jurisdicionais e procura sempre ressalvar vantagens aos países em desenvolvimento, visto que estes não têm meios suficientes para promover a efetivação do escopo do Tratado.

\footnotetext{
${ }^{3}$ Nas palavras de Usberco e Salvador: “ A interrupção imediata do uso do CFC permitirá que a camada de ozônio se regenere apenas num período de tempo estimado em 150 anos.". (2000, p. 216)

4. "Substâncias alternativas" significa substâncias que reduzem, eliminam ou evitam efeitos adversos sobre a camada de ozônio. (Convenção de Viena, 1985, disponível em <http://www.onu-brasil.org.br/doc_ozonio.php> acesso em 5 de outubro de 2007).
} 
Nesse contexto, no art. $2^{\circ}$, há o que é denominado "Obrigações Gerais" no texto da Convenção:

As Partes devem tomar medidas adequadas, de acordo com os dispositivos desta Convenção, bem como dos protocolos em vigor nos quais sejam parte, a fim de proteger a saúde humana e o meio ambiente contra efeitos adversos que resultem, ou possam resultar, de atividades humanas que modifiquem, ou possam modificar, a camada de ozônio. (Convenção de Viena, 1985, disponível em <http://www.onu-brasil.org.br/doc_ozonio.php> acesso em 5 de outubro de 2007).

Nesse sentido, para adotar tais medidas, o texto procura velar pela harmonização da legislação e das ações dos Estados-parte. No texto em questão:

adotar medidas legislativas ou administrativas apropriadas e cooperar na harmonização de políticas adequadas para controlar, limitar, reduzir ou evitar atividades humanas sob sua jurisdição ou controle, caso se verifique que tais atividades têm, ou provavelmente terão, efeitos adversos que resultem de modificações, ou prováveis modificações da camada de ozônio.

Outrossim, a autora Mireille Delmas-Marty (2003, p. 117-118) versa em sua obra sobre a harmonização. Nesse sentido, harmonizar seria fazer com que existisse uma aproximação dos sistemas entre si, o que não implicaria suprimir todas as diferenças, e sim reconhecê-las dentro de um pluralismo jurídico ordenado e uma concepção tolerante do Direito. Dessa forma, pode-se afirmar que qualquer tentativa de combate ao uso indiscriminado do CFC seria inócua sem uma harmonização de normas e uma cooperação entre os Estados, haja vista o caráter universal que possui a camada de ozônio, um bem da humanidade.

O Protocolo de Montreal sobre o uso de CFC, de 1987 veio na mesma esteira da Convenção de Viena. Os objetivos são regulamentar as formas que se dará a cooperação de tecnologias alternativas ao uso de gazes nocivos à camada de ozônio. No preámbulo do texto do Protocolo:

Reconociendo que hay que tomar disposiciones especiales para satisfacer las necesidades de los países en desarrollo, incluso la aportación de recursos financieros adicionales y el acceso a las tecnologías pertinentes, teniendo en cuenta que la magnitud de los fondos necesarios es previsible y que cabe esperar que los fondos produzcan un aumento sustancial de la capacidad del mundo para abordar el problema, científicamente comprobado, del agotamiento del ozono y sus nocivos efectos,

Tomando nota de las medidas preventivas para controlar las emisiones de ciertos clorofluorocarbonos que ya se han tomado en los planos nacional y regional, 
Considerando la importancia de promover la cooperación internacional en la investigación, el desarrollo y la transferencia de tecnologías alternativas, en relación con el control y la reducción de las emisiones de sustancias que agotan la capa de ozono, teniendo presentes en particular las necesidades de los países en desarrollo, han convenido lo siguiente (...). (Protoloco de Montreal, disponível no site <http://www.unep.org/Ozone/pdfs/Montreal-ProtocolBooklet-sp.doc > acesso em 8 de outubro de 2007.

Dessa forma, o escopo do protocolo é regulamentar como se dará a redução do uso e a cooperação internacional no tema. Para tanto, o protocolo traz questões referentes aos tipos de gazes nocivos à ozonosfera, classificando-os, faz menções às quantidades que os países se comprometem a reduzir, à metodologia aplicada para medir a quantificação dos gazes, à regulamentação do comércio, entre outras medidas técnicas. Pode-se afirmar que a Convenção de Viena é um marco teórico que passa a ser aplicado através das normas técnicas estabelecidas no Protocolo.

\subsection{Os Direitos Humanos de terceira geração na Constituição Venezuelana}

O direito ao meio ambiente encontra-se expressamente previsto na constituição venezuelana. Ele está previsto nos artigos 127 à 129 da carta, em capítulo intitulado: “dos direitos ambientais". Consta que é responsabilidade de todas as gerações preservar o meio-ambiente. Igualmente, imputa ao Estado o dever estatal garantir um ambiente saudável para os seres humanos. A transcrição original da Constituição é a seguinte:

\section{Capítulo IX \\ De los Derechos Ambientales}

Artículo 127. Es un derecho y un deber de cada generación proteger y mantener el ambiente en beneficio de sí misma y del mundo futuro. Toda persona tiene derecho individual y colectivamente a disfrutar de una vida y de un ambiente seguro, sano y ecológicamente equilibrado. El Estado protegerá el ambiente, la diversidad biológica, los recursos genéticos, los procesos ecológicos, los parques nacionales y monumentos naturales y demás áreas de especial importancia ecológica. El genoma de los seres vivos no podrá ser patentado, y la ley que se refiera a los principios bioéticos regulará la materia.

Es una obligación fundamental del Estado, con la activa participación de la sociedad, garantizar que la población se desenvuelva en un ambiente libre de contaminación, en donde el aire, el agua, los suelos, las costas, el clima, la capa de ozono, las especies vivas, sean especialmente protegidos, de conformidad con la ley.

Artículo 128. El Estado desarrollará una política de ordenación del territorio atendiendo a las realidades ecológicas, geográficas, poblacionales, sociales, culturales, económicas, políticas, de acuerdo con las premisas del desarrollo sustentable, que incluya la información, consulta y participación ciudadana. Una ley orgánica desarrollará los principios y criterios para este ordenamiento. 
Artículo 129. Todas las actividades susceptibles de generar daños a los ecosistemas deben ser previamente acompañadas de estudios de impacto ambiental y socio cultural. El Estado impedirá la entrada al país de desechos tóxicos y peligrosos, así como la fabricación y uso de armas nucleares, químicas y biológicas. Una ley especial regulará el uso, manejo, transporte y almacenamiento de las sustancias tóxicas y peligrosas.

En los contratos que la República celebre con personas naturales o jurídicas, nacionales o extranjeras, o en los permisos que se otorguen, que afecten los recursos naturales, se considerará incluida aun cuando no estuviera expresa, la obligación de conservar el equilibrio ecológico, de permitir el acceso a la tecnología y la transferencia de la misma en condiciones mutuamente convenidas y de restablecer el ambiente a su estado natural si éste resultara alterado, en los términos que fije la ley.

De tal exposição pode-se observar que a Constituição mostra-se aberta às questões atinentes a preservação do meio ambiente, ao reconhecê-lo como Direito Fundamental. Nesse sentido, deve-se ressaltar que o momento histórico, 1999, da elaboração de tal carta já era marcado por preocupações ambientais. Nesse período, já existiam várias convenções e protocolos internacionais, nos quais a Venezuela é signatária, buscando a proteção dos Direitos Humanos de terceira geração.

\subsection{O caso do CFC na suprema Corte Venezuelana}

O caso teve início originariamente no "Tribunal Supremo de Justicia" da Venezuela. A empresa Refrimaster, demandante, recorreu à suprema corte contra decisão do ministério do meio ambiente venezuelano, que não lhe concedeu permissão para importar diclorodifluorometanos, CFC-12 e CFC-114 para finalidades farmacêuticas (fabricação de inaladores para asmáticos). No entanto, tais substâncias são nocivas à camada de ozônio. O meio processual que tal questão chegou à suprema corte foi uma ação cautelar de amparo, prevista na legislação venezuelana, que concede à corte máxima a competência de conhecer sobre atos administrativos dos ministérios.

A empresa alegou em seu favor que o ministério da saúde havia concedido a permissão, com fulcro no fato de estar de acordo com a resolução $\mathrm{N}^{\circ} 16537$ do "Ministerio de Salud y Desarrollo Social" em 1999, tendo assim a empresa direito adquirido. Tal entendimento teve base no artigo 20 do Decreto $\mathrm{N}^{\circ} 3220$, dispositivo

sobre "Normas para Reducir el Consumo de las Sustancias Agotadoras de la Capa de Ozono". O ministério interpretou que a quantidade do produto a ser exportada se enquadrava nos padrões legais.

Na decisão: 
Respecto al amparo constitucional interpuesto, la Sala observa que la empresa presuntamente agraviada (Refrigeración Master Metropolitana, C. A REFRIMASTER), argumenta en su libelo, que la Dirección General de Calidad Ambiental del Ministerio del Ambiente y de los Recursos Naturales, mediante oficios Nros. 00722 y 00725 , ambos de fecha 20 de julio de 2000, le negó el permiso de importación para gas refrigerante CFC12 y CFC-114 diclorodifluorometanos, para ser utilizados en especialidades farmacéuticas, permiso de importación a la que tiene la recurrente derecho adquirido -según alega- de conformidad a la autorización otorgada por el Ministerio de Salud y Desarrollo Social a través de la Resolución No 16537 de fecha 29 de diciembre de 1999 (según consta en anexo marcado "G"). Por otra parte, cabe destacar que la referida decisión de la Dirección General de Calidad Ambiental del Ministerio del Ambiente y de los Recursos Naturales se fundamentó en los artículos $4^{\circ}$ y $9^{\circ}$ del Decreto Presidencial No 3.220 del 13 de enero de 1999, los cuales, según expone la representación judicial de la actora, adolecen de vicios de inconstitucionalidad e ilegalidad que no pueden ser revisados en esta decisión ya que cualquier pronunciamiento al respecto constituye materia que debe ser resuelta al decidir el fondo de la nulidad interpuesta. (Decisão do Tribunal Supremo de Justicia da Venezuela, $\mathrm{n}^{\circ}$ 0809, de 2002, disponível em <http://www.tsj.gov.ve/decisiones/spa/marzo/00458-120302-0908.htm> acesso em 7 de outubro de 2007.

Ademais, a parte autora invoca o direito à igualdade, previsto pela constituição venezuelana, alegando que outras empresas teriam sido beneficiadas pela permissão de exportação. Também, argüiu que o seu direito à liberdade de empresa estava sendo violado pela negativa do ministério, artigo 112 da Contituição Venezuelana. Por fim, alegou que o direito universal à saúde, artigo 83 da mesma carta, estaria sendo desrespeitado. Na decisão, "finalmente, la recurrente también considera que el referido acto impugnado viola el derecho a la salud (artículo 83 eiusdem) de un gran número de venezolanos que padecen de asma" (Decisão do Tribunal Supremo de Justicia da Venezuela, $\quad \mathrm{n}^{\mathrm{o}} \quad$ 0809, de 2002, disponível em <http://www.tsj.gov.ve/decisiones/spa/marzo/00458-120302-0908.htm> acesso em 7 de outubro de 2007.)

Nesse sentido, pode-se observar a existência de um conflito entre o direito à saúde e o direito ao meio ambiente, ambos protegidos pela carta maior venezuelana. $\mathrm{O}$ Direito dos asmáticos à fabricação do produto para seu tratamento foi invocado pela empresa Refrimaster que alegou que iria repassar o pedido a uma empresa farmacêutica, fabricante de inaladores. Por outro lado, o ministério do meio ambiente venezuelano entendeu que o direito ao meio ambiente era um bem maior e que, portanto, a permissão de importação não poderia ser concedida. Da mesma forma, a destruição da camada de 
ozônio seria nociva à saúde de todos os cidadãos, sendo o direito à saúde também invocado.

A suprema corte venezuelana assim decidiu:

De lo expuesto se infiere, que igualmente en el presente caso, la parte actora ha señalado de manera genérica los daños o el perjuicio que la aplicación del referido Decreto pudiera ocasionarle y adicionalmente la Sala considera que no ha podido verificarse la presunción de buen derecho alegada por la recurrente, dado que no ha quedado demostrado que las restricciones derivadas de la aplicación del referido Decreto, privan toda alternativa del ejercicio de los derechos constitucionales alegados por la quejosa. De manera que, la proporción o justa medida del ejercicio de un derecho constitucional está determinada por los efectos que sobre otros derechos igualmente tutelados por el ordenamiento constitucional, puedan tener los medios escogidos para ejercerlos. De allí que cualquier restricción a la utilización de determinados medios debe perseguir como finalidad la protección de un valor o interés constitucional, que en casos como el de autos, resulta determinante. Por las razones expuestas, esta Sala considera improcedente la medida cautelar solicitada. Así se decide. Decisão do Tribunal Supremo de Justicia da Venezuela, $n^{\circ}$ 0809, de 2002, disponível em <http://www.tsj.gov.ve/decisiones/spa/marzo/00458-120302-0908.htm> acesso em 7 de outubro de 2007.).

Dessa forma, a corte entendeu que o Direito a um meio ambiente saudável era uma questão ambiental de extrema relevância. Faz-se também importante ressaltar que tal decisão, embora tenha invocado apenas normas nacionais, está de acordo com os tratados internacionais que visam a garantir um meio ambiente saudável. Portanto, a decisão não garante esse direito apenas para os cidadãos nacionais, mas sim garante para a população mundial, visto que as consequiências da nocividade do gás prejudicam a população em escala global, ameaçada pela crescente destruição da camada de ozônio.

Essa decisão pode ser colocada na chamada contra-globalização, cunhada por Boaventura de Souza Santos (2001, p. 70-73). A decisão invoca o Direito coletivo e universal de todos em relação a um meio-ambiente saudável, contestando o interesse econômico de um ente privado, no caso a empresa Refrimaster.

Foi desenvolvido pelo grupo com o fito de objetivar os dados colhidos nas decisões estudas uma grade padrão ${ }^{5}$. Essa foi a tabela desenvolvida para o caso em estudo:

\section{\begin{tabular}{|l|l|}
\hline Elementos de análise & Descrição
\end{tabular}}

\footnotetext{
${ }^{5}$ A grade apresentada foi elaborada pelos autores do artigo e apresentada na Uniceub, Brasília, em evento intitulado Internacionalização do Direito, pela coordenadora do projeto. Estava presente a prof ${ }^{\mathrm{a}}$. Mireille Delmas-Marty. O objetivo foi inserir o projeto de pesquisa no âmbito do Grupo Figuras da Internacionalização do Direito, coordenado pela professora citada.
} 


\begin{tabular}{|c|c|c|c|c|}
\hline \multicolumn{3}{|l|}{ País } & \multicolumn{2}{|l|}{ Venezuela } \\
\hline \multicolumn{3}{|c|}{ Tribunal } & \multicolumn{2}{|c|}{ Tribunal Supremo de Justicia } \\
\hline \multicolumn{3}{|c|}{ Meio Processual } & \multicolumn{2}{|l|}{ Amparo Cautelar } \\
\hline \multirow[t]{4}{*}{ Atores } & & & Públicos & Privados \\
\hline & \multicolumn{2}{|c|}{ Demandante } & & $\begin{array}{l}\text { Refrigeracion } \\
\text { Master } \\
\text { Metropolitana } \\
\text { C.A. } \\
\text { (Refrimaster) }\end{array}$ \\
\hline & \multicolumn{2}{|c|}{ Demandado } & $\begin{array}{l}\text { Ministro del } \\
\text { Ambiente y de los } \\
\text { Recursos } \\
\text { Naturales } \\
\text { (Venezuela) }\end{array}$ & \\
\hline & \multicolumn{2}{|c|}{ Interessados (amicus curiae) } & & \\
\hline \multicolumn{3}{|c|}{ Pretensão } & \multicolumn{2}{|c|}{$\begin{array}{l}\text { Contestar decisão do ministro do meio } \\
\text { ambiente venezuelano que proibiu a } \\
\text { empresa de importar CFC } 12 \text { e CFC } \\
\text { 14, que seriam utilizados para fins } \\
\text { farmacêuticos, sob a alegação de tais } \\
\text { substâncias serem danosas à camada } \\
\text { de ozônio. }\end{array}$} \\
\hline \multirow{3}{*}{\multicolumn{2}{|c|}{$\begin{array}{l}\text { Marco normativo } \\
\text { envolvido }\end{array}$}} & Nacional & \multicolumn{2}{|c|}{$\begin{array}{l}\text { Constituição } \quad \text { Bolivariana } \\
\text { Venezuela, artigos } 83 \text { e } 112 . \\
\text { Decreto Presidencial No } 3.220 .\end{array}$} \\
\hline & & Regional & & \\
\hline & & Global & & \\
\hline \multicolumn{3}{|c|}{ Sentença } & \multicolumn{2}{|c|}{$\begin{array}{l}\text { O amparo cautelar foi indeferido. } \mathrm{O} \\
\text { Tribunal Supremo argumentou que o }\end{array}$} \\
\hline
\end{tabular}




\begin{tabular}{|l|l|}
\hline & $\begin{array}{l}\text { interesse em preservar a camada de } \\
\text { ozônio prepondera sobre o interesse na } \\
\text { utilização de CFCs para fabricação de } \\
\text { inaladores para asmáticos e, } \\
\text { principalmente, sobre o direito à } \\
\text { liberdade de empresa. }\end{array}$ \\
\hline Conclusão & $\begin{array}{l}\text { A corte decidiu o conflito priorizando } \\
\text { o bem-estar geral da população, } \\
\text { invocando o direito a um meio } \\
\text { ambiente saudável. Desprezou o } \\
\text { interesse econômico da empresa, que } \\
\text { argüiu sofrer prejuízos irreparáveis } \\
\text { devido à proibição da importação de } \\
\text { CFC 12 e CFC 14. }\end{array}$ \\
\hline
\end{tabular}

\section{CONSIDERAÇÕES FINAIS}

Os Direitos Humanos ditos de terceira geração ou transindividuais estão muito em voga no cenário mundial hodierno. É importante salientar que a consciência da população vem crescendo à medida que os indivíduos que compõem a sociedade passam a compreender que as formas de vida conhecidas dependem da preservação do meio ambiente para poderem continuar a existir.

O caso específico dos CFCs, gazes que destroem a ozonosfera é um grande exemplo de tal situação. É importantíssimo que a camada de ozônio seja preservada, com o objetivo de coibir a entrada excessiva dos raios ultravioletas no planeta.

O Projeto denominado "O sistema autônomo de solução de controvérsias do Mercosul e as cortes supremas de justiça dos seus países membros: Direitos Humanos e perspectivas para a consolidação da cidadania" vem, nesse sentido, contribuir para fazer um mapeamento jurisprudencial acerca dos direitos ao meio ambiente e à saúde nas Cortes Supremas do Mercosul e em seu sistema autônomo de solução de controvérsias. Assim, a análise do caso venezuelano é de grande valia para o estudo, pois se trata de uma decisão que priorizou um Direito Humano coletivo como o direito a um meioambiente salutar em detrimento de interesses econômicos. 
São decisões como essas que fazem com que a jurisdição ainda seja um meio para possibilitar a efetivação dos direitos humanos e a luta contra a devastação da natureza, que, infelizmente, vem assolando o Planeta Terra.

\section{REFERÊNCIAS BIBLIOGRÁFICAS}

Bobbio, Norberto. A era dos Direitos. Tradução de Carlos Nelson Coutinho. Rio de Janeiro, Campus, 1992.

Convenção de Viena - Camada de Ozônio. Disponível em <http://www.onubrasil.org.br/documentos_convencoes.php> acesso em 9 de outubro de 2007.

Delmas-Marty, Mireille. Três Desafios pra um Direito Mundial. Tradução de Fauzen Hassan Choukr. Rio de Janeiro: Lúmen Júris, 2003.

Delmas-Marty, Mireille. Le Relatif et l'Universelle. Paris: Seul, 2004.

Britannica, Enciclopédia. Micropaedia, v.5. Chicago, 1993.

Protocolo de Montreal. Disponível em

<www.mct.gov.br/index.php/content/view/47613.html - 49k> acesso em 9 de outubro de 2007.

Souza Santos, Boaventura de (org). Globalização, fatalidade ou utopia? Porto, Afrontamento, 2001.

Sarlet, Ingo Wolfgang. A eficácia dos Direitos Fundamentais. Porto Alegre: Livraria do Advogado, 2005.

Usberco e Salvador. Química 1. São Paulo, Editora Saraiva, 2000.

VENEZUELA. Constitución de la Republica Bolivariana de Venezuela. Disponível em < http://www.tsj.gov.ve/legislacion/constitucion1999.htm> acesso em 2 de outubro de 2007.

VENEZUELA. Suprema Corte Justicia. Decision de amparo cautelar no . 0809, de 2002. Disponível em < http://www.tsj.gov.ve/decisiones/spa/marzo/00458-120302-0908.htm> acesso em 3 de outubro de 2007.

Wikipédia, a enciclopédia livre. Disponível em <http://pt.wikipedia.org/wiki/P\%C3\%A1gina_principal> acesso em 10 de outubro de 2007. 
